\title{
ANALISIS PEMODELAN TARIKAN PERGERAKAN DEPARTMENT STORE (STUDI KASUS DI WILAYAH SOLORAYA)
}

\author{
Syafi'i'); Slamet Jauhari Legowo 2); Mahmud Nur Kholis ${ }^{3)}$ \\ 1), 2) Dosen Pembimbing Skripsi \\ 3) Mahasiswa Teknik Sipil \\ Jalan Ir. Sutami Nomor 36A Kentingan Surakarta 57126 \\ Telepon (0271) 647069 Psw. 120,121, 08112633314 , Fax. (0271) 634524 \\ Email : mahmudnurk@student.uns.ac.id
}

\begin{abstract}
Transportation is basic need of region that used as an effort to improve the welfare of its population. Transportation planning is absolutely necessary to find themost efficient solution from the movement interaction. The movement begins with trip generation. Department Store is one of the land uses that generates mass movement and have large size. Because of that, study needs to be done about the attraction of movement of department store in Soloraya with linear regression analysis. With that, we can know what factors that influence the attraction of movement in Soloraya and the best model that can be made. Research was conducted on Saturday - Sunday, 27 - 28 April 2019 at the peak. hour of mall which is the peak. hour of each mall is different. Collected vehicle data then converted to passenger car unit (pcu). The variables used are the attraction of vehicle movements (Y), total land area (X1), and total building area (X2). Abnalysis using SPSS software with enter and stepwise method. V arious data tests were carried out to get the result according to BLUE (Best Linear Unbias Estimator) conditions. The results of the analysis and tests that have been carried out concluded that the regression model of the stepwise method is the best model, it is $Y=14.455+0.005 X 2$ which X2 is total building area. So it was concluded that the biggest impact of the attraction of movement influenced by total building area.
\end{abstract}

Keywords : linear regression, the attraction of movement, department store, enter method, stepwise method

\begin{abstract}
Abstrak
Transportasi merupakan kebutuhan dasar dari sebuah wilayah yang digunakan sebagai usaha untuk meningkatkan kesejahteraan penduduknya. Perencanaan transportasi mutlak diperlukan untuk mencari solusi paling efisien dari adanya interaksi pergerakan. Pergerakan diawali dengan adanya bangkitan dan tarikan pergerakan (Trip Generation). Department Store adalah salah satu tata guna lahan yang membangkitkan pergerakan secara massal dan memiliki ukuran yang besar. Karena itu dilakukan studi mengenai tarikan pergerakan pada department store yang ada di Soloraya menggunakan analisis regresi linier. Dengan begitu dapat diketahui faktor apa yang mempengaruhi tarikan pergerakan kendaraan ke department store di Soloraya serta model terbaik yang dapat dibuat. Penelitian dilakukan pada hari Sabtu - Minggu, 27 - 28 April 2019 pada jam puncak mall dimana tiap mall jam puncaknya berbeda-beda. Data kendaraan yang terkumpul kemudian dikonversikan menjadi satuan mobil penumpang. Variabel yang digunakan adalah tarikan pergerakan kendaraan (Y), total luas lahan (X1), dan total luas bangunan (X2). Analisis menggunakan software SPSS dengan metode enter dan stepwise. Dilakukan berbagai uji data untuk mendapatkan hasil sesuai syarat BLUE (Best Linear Unbias Estimator). Hasil analisis dan uji yang telah dilakukan disimpulkan bahwa model regresi dari metode Stepwise adalah model terbaik, yaitu $\mathrm{Y}=14.455+0.005 \mathrm{X} 2$ dimana X2 adalah total luas bangunan. Sehingga disimpulkan bahwa pengaruh terbesar tarikan pergerakan kendaraan dipenga ruhi oleh total luas bangunan.
\end{abstract}

Kata Kunci : regresi linier, tarikan pergerakan, department store, metode enter, metode stepwise 


\section{PENDAHULUAN}

Pergerakan diawali dengan adanya bangkitan dan tarikan pergerakan. Setiap wilayah memiliki faktor untuk membangkitkan (production) atau menarik (attraction) pergerakan, tergantung pada tata guna lahannya. Salah satu tujuan pergerakan yang dilakukan masyarakat adalah pergerakan dengan tujuan pemenuhan kebutuhan ekonomi atau berbelanja. Pergerakan ini memiliki rentang waktu yang tidak terbatas dan tujuan perjalanan yang beraneka ragam. Salah satu tujuan pergerakan ini adalah department store. Department store adalah satu dari sekian banyak pilihan tujuan pusat perbelanjaan.

Wilayah Soloraya sebagai wilayah yang terus bertumbuh memiliki potensi perdagangan yang cukup besar. Letak Soloraya yang strategis berdekatan dengan provinsi Yogyakarta di selatan, Semarang di utara, serta provinsi Jawa Timur di timur, menjadikan Soloraya wilayah yang memiliki perkembangan yang pesat. Hal ini ditunjukkan dengan bertambahnya pembangunan pusat perbelanjaan termasuk department store dari waktu ke waktu. Setidaknya ada empat lokasi yang dapat dikategorikan sebagai department store di Soloraya, yaitu Hartono Mall, Matahari Singosaren, Solo Square, dan Solo Grand Mall. Dengan adanya department store yang berdiri di Soloraya ini, otomatis akan menarik pergerakan secara massif. Oleh karena itu diperlukan studi yang menitikberatkan pada tarikan pergerakan kendaraan ke dalam department store untuk mengetahui seberapa besar department store di Soloraya dapat menarik pergerakan serta faktor-faktor yang mempengaruhinya, sehingga nantinya dapat dibuat kebijakan maupun aturan berkaitan dengan hal tersebut.

\section{LANDASAN TEORI}

\section{A. Sistem Transportasi Makro}

Sistem transportasi makro merupakan gabungan dari beberapa system transportasi mikro. Sistem transportasi mikro terdiri dari system kegiatan, system jaringan, system pergerakan, dan system kelembagaan yang kesemuanya saling terkait dan mempengaruhi.

\section{B. Perencanaan Transportasi}

Perencanaan transportasi merupakan sebuah proses yang bertujuan untuk mengembangkan system transportasi yang memungkinkan manusia dan barang bergerak secara aman dan murah serta efisien dengan sumber daya yang ada.

\section{Model Perencanaan Transportasi Empat Tahap}

Model perencanaan transportasi empat tahap (four stages transport model) terdiri dari bangkitan dan tarikan pergerakan (trip generation), distribusi pergerakan (trip distribution), pemilihan model (modal choice), dan pembebanan lalu lintas (traffic assignment).

\section{Bangkitan dan Tarikan Pergerakan}

Bangkitan pergerakan| adalah tahapan pemodelan yang memperkirakan jumlah pergerakan yang berasal dari suatu zona atau tata guna lahan dan jumlah pergerakan yang tertatik ke suatu zona atau tata guna lahan. Pergerakan lalu lintas merupakan fungsi tata guna lahan yang menghasilkan pergerakan lalu lintas. Bangkitan lalu lintas ini mencakup:

1. Lalu lintas yang meninggalkan suatu lokasi.

2. Lalu lintas yang menuju atau tiba ke suatu lokasi.

Hasil keluaran perhitungan bangkitan pergerakan adalah jumlah kendaraan, orang, atau angkutan barang persatuan waktu. Bangkitan dan tarikan pergerakan ini tergantung pada dua aspek tata guna lahan, yaitu jenis tata guna lahan dan jumlah aktivitas (dan intensitas) pada tata guna lahan tersebut. Tata guna lahan yang berbeda memiliki ciri pergerakan yang berbeda pula. 


\section{E. Analisis Regresi}

Analisis regresi adalah sutu model analisis data yang menggambarkan hubungan fungsional antara variabel respon dengan satu atau beberapa variabel prediktor. Beberapa asumsi statistik yang diperlukan dalam analisis regresi adalah:

1. Variabel tak bebas adalah fungsi linier dari variabel bebas. Jika hubungan tidak linier, maka harus ditransformasikan agar menjadi linier.

2. Variabel bebas adalah tetap dan telah terukur tnapa kesalahan.

3. Tidak ada korelasi antara variabel bebas.

4. Nilai variabel tak bebas harus terdistribusi normal atau mendekati normal.

Ada dua metode yang dapat digunakan untuk analisis regresi, yaitu metode enter dan metode stepwise. Metode enter adalah metode untuk menghasilkan model dengan memilih semua variabel bebas dalam persamaan regresi. Sedangkan metode stepwise adalah metode dengan cara memilih variabel bebas yang memiliki signifikansi kuat dalam pemodelan.

\section{F. Analisis Regresi Linier Sederhana}

Analisis regresi linier sederhana digunakan untuk mendapatkan hubungan matematis dalam bentuk suatu persamaan antara variabel tak bebas dengan variabel bebas tunggal. Regresi linier sederhana hanya memiliki satu perubahan regresi linier untuk populasi dengan rumus umum sebagai berikut.

$$
\mathrm{Y}=\mathrm{a}+\mathrm{bX}
$$

dimana:

Y : variabel tidak bebas (kriterium)

a : konstanta regresi

b $\quad$ : koefisien arah regresi linier yang menyatakan perubahan rata-rata variabel $\mathrm{Y}$ untuk setiap perubahan variabel $\mathrm{X}$ sebesar satu unit satuan

X : variabel bebas (prediktor)

\section{G. Analisis Regresi Linier Berganda}

Analisis regresi linier berganda digunakan untuk memprediksi berubahnya nilai variabel tertentu bila variabel lain berubah. Dikatakan regresi berganda, karena jumlah variabel bebas lebih dari satu. Maka rumus umumnya adalah sebagai berikut.

dimana:

$$
\mathrm{Y}=\mathrm{b}_{0}+\mathrm{b}_{1} \mathrm{X}_{1}+\mathrm{b}_{2} \mathrm{X}_{2}+\ldots+\mathrm{b}_{\mathrm{n}} \mathrm{X}_{\mathrm{n}}
$$

Y $\quad$ : variabel tidak bebas (kriterium)

$\mathrm{b}_{0} \quad$ : konstanta

$\mathrm{b}_{1}, \mathrm{~b}_{2}, \ldots \mathrm{b}_{\mathrm{n}} \quad$ : koefisien prediktor 1 , koefisien prediktor $2, \ldots$ koefisien prediktor ke- $\mathrm{n}$

$\mathrm{X}_{1}, \mathrm{X}_{2}, \ldots \mathrm{X}_{\mathrm{n}} \quad$ : variabel bebas (prediktor) 1 , variabel bebas (prediktor) $2, \ldots$ variabel bebas (prediktor) ke-n

\section{METODOLOGI PENELITIAN}

Metode penelitian menggunakan metoded deskriptif analitis, dimana data awal dikumpulkan dan dianalisis, kemudian dijelaskan dan dianalisa sehingga menghasilkan kesimpulan atas permasalahan yang ada.

\section{Lokasi dan Waktu Penelitian}

Penelitian mengambil lokasi di empat department store di Soloraya, yaitu:

1. Matahari Singosaren

2. Hartono Mall Solobaru

3. Solo Square 


\section{Solo Grandmall}

Penelitian berupa pengambilan data primer dan sekunder. Pengambilan data primer dilakukan dengan cara survey langsung yang dilakukan pada akhir bulan April 2019 pada jam puncak setiap department store yang terjadi pada akhir pekan.

\section{Sumber Data}

\section{Data Primer}

Data primer didapat dari survey lapangan dengan melakukan pencatatan kendaraan masuk ke dalam department store sebagai tarikan pergerakan kendaraan. Pencatatan dilakukan dalam selang interval setiap 10 menit selama satu jam..

\section{Data Sekunder}

Data sekunder didapat dari data yang terlah tersedia terkait dengan department store. Data sekunder yang diperlukan adalah data total luas lahan dan total luas bangunan.

\section{Analisis Data}

Analisis data menggunakan metode regresi linier berganda. Penggunaan regresi linier dimaksudkan untuk peramalan, pemilihan variabel yang berpengaruh, pembuatan model, dan mengetahui hubungan antarvariabel. Pengolahan data menggunakan software SPSS yang mampu menganalisa data yang besar serta memiliki alat uji statistik lengkap di dalamnya. Metode pengolahan data menggunakan metode enter dan stepwise.

\section{HASIL DAN PEMBAHASAN}

Data primer yang telah didapat kemudian dikonversikan menjadi satuan mobil penumpang (smp), dengan cara mengkalikannya dengan nilai ekivalensi mobil penumpang (emp). Menurut Manual Kapasitas Jalan Indonesia (MKJI), nilai emp untuk masing-masing jenis kendaraan LV (light vehicle) dan MC (motorcycle) adalah 1 dan 0.4. Berikut rekapitulasi data primer yang telah dikonversi dengan data sekunder.

Tabel 1. Rekapitulasi Data Primer dan Sekunder

$$
\text { Data Primer }(\mathrm{Y}) \quad \text { Data Sekunder }(\mathrm{X})
$$

\begin{tabular}{cccc}
\hline & Data Primer $(\mathrm{Y})$ & \multicolumn{2}{c}{ Data Sekunder $(\mathrm{X})$} \\
Lokasi Survey & $\begin{array}{c}\text { Tarikan Kendaraan (smp) } \\
\text { kend/jam }\end{array}$ & $\begin{array}{c}\text { Total Luas Lahan } \\
\left(\mathrm{m}^{2}\right) \mathrm{X}_{1}\end{array}$ & $\begin{array}{c}\text { Total Luas bangunan } \\
\left(\mathrm{m}^{2}\right) \mathrm{X}_{2}\end{array}$ \\
\hline \hline Matahari Singosaren & 126 & 8030 & 19.800 \\
Hartono Mall & 584 & 36.500 & 100.000 \\
Solo Grand Mall & 376 & 12.080 & 63.000 \\
Solo Square & 400 & 25.000 & 79.200 \\
\hline
\end{tabular}

\section{Analisis Korelasi}

Di bawah ini merupakan hasil analisis korelasi yang telah dilakukan menggunakan software SPSS. 
Tabel 2. Koefisien Korelasi

\begin{tabular}{cccc}
\hline Korelasi & $\begin{array}{c}\text { Tarikan } \\
\text { Kendaraan }\end{array}$ & Luas Total Lahan & $\begin{array}{c}\text { Luas Total } \\
\text { Bangunan }\end{array}$ \\
\hline \hline Tarikan & 1 & 0.897 & 0.985 \\
$\begin{array}{c}\text { Kendaraan } \\
\text { Luas Total Lahan }\end{array}$ & & 1 & 0.912 \\
Luas Total & & 1 \\
Bangunan & & & \\
\hline
\end{tabular}

Dari tabel di atas terlihat nilai koefisien korelasi yang cukup tinggi antara variabel bebas dengan variabel terikat dengan kisaran nilai $0.912-0.985$. Nilai tersebut cukup tinggi karena mendekati nilai 1 di setiap hubungannya. Nilai paling tinggi terjadi antara variabel terikat dengan total luas bangunan, yakni sebesar 0.985. Hal ini mengindikasikan hubungan yang sangat kuat antara variabel terikat dengan variabel bebas. Selain itu, nilai koefisien determinasi $\left(\mathrm{R}^{2}\right)$ antara variabel terikat dengan tiap variabel bebas juga tinggi.
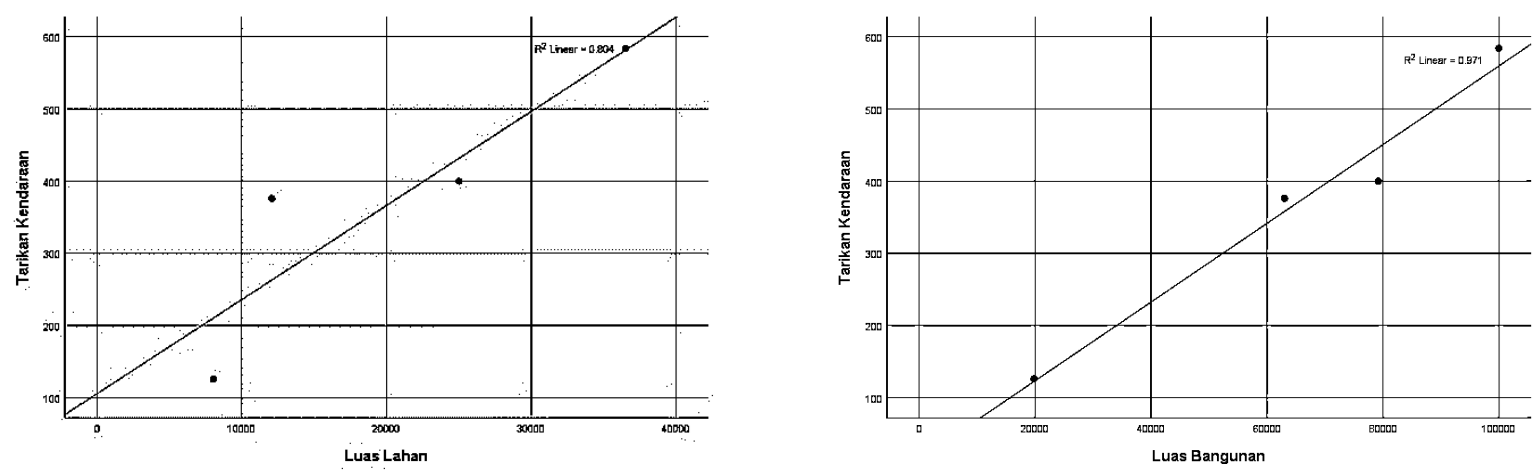

Gambar 1. Grafik Hubungan antara Tarikan Kendaraan dengan Luas Lahan (kirr) dan Luas Bangunan (kanan)

Grafik di atas menunjukkan nilai $\mathrm{R}^{2}$ antara tarikan kendaraan dengan luas lahan sebesar 0.804 dan dengan luas bangunan sebesar 0.971 .

\section{Analisis Persamaan Regresi}

Berdasar perhitungan menggunakan software SPSS, didapat persamaan regresi sebagai berikut.

a. Metode Enter

$$
\mathrm{Y}_{1}=14.059+0.006 \mathrm{X}_{2}
$$

b. Metode Stepwise

$$
\mathrm{Y}_{2}=14.455+0.005 \mathrm{X}_{2}
$$

\section{Pemilihan Model Terbaik}

Setelah didapatkan model persamaan, dilakukan berbagai uji untuk mencari dan mendapatkan model terbaik dari metode yang telah dilakukan. Berikut hasil pengujiannya.

Tabel 3. Rekapitulasi Serangkaian Analisis dan Pengujian Model

\begin{tabular}{ccc}
\hline Uji & $\begin{array}{c}\text { Enter } \\
\mathrm{Y}_{1}=14.059+0.006 \mathrm{X}_{2}\end{array}$ & $\begin{array}{c}\text { Stepwise } \\
\mathrm{Y}_{1}=14.455+0.005 \mathrm{X}_{2}\end{array}$ \\
\hline $\mathrm{R}$ & 0.985 & 0.985 \\
$\mathrm{R}^{2}$ & 0.971 & 0.971 \\
Uji-t & $\mathrm{a}: 0.204<12.706$ & $\mathrm{a}: 0.303<4.302$
\end{tabular}

Dilanjutkan 


$\begin{array}{ccc}\text { Lanjutan } & \text { (tidak signifikan) } & \text { (tidak signifikan) } \\ & \mathrm{b}: 2.407<12.706 & \mathrm{~b}: 8.197<4.302 \\ & (\text { tidak signifikan) } & \text { (signifikan) } \\ \text { Uji-f } & 16.812<199 & 67.191>18.51 \\ & \text { (tidak dapat menjelaskan } & \text { (dapat menjelaskan } \\ \text { Uji Linearitas } & \text { variansi) } & \text { variansi) } \\ \text { Uji Nonautokorelasi } & \text { Sampel tidak cukup } & \text { Sampel tidak cukup } \\ \text { Uji Nonmultikolinearitas } & \text { Ada multikolinearitas } & \text { Nonmultikolinearitas } \\ \text { Uji Normalitas } & \text { Terpenuhi } & \text { Terpenuhi } \\ \text { Uji Heterokedastisitas } & \text { Tidak terjadi } & \text { Tidak terjadi }\end{array}$

Dari tabel rekapitulasi di atas, disimpulkan model terbaik adalah model:

$$
\mathrm{Y}=14.455+0.005 \mathrm{X}_{2}
$$

dimana:

$\mathrm{Y} \quad$ : tarikan pergerakan kendaraan (smp/jam)

$\mathrm{X}_{2} \quad$ : total luas bangunan $\left(\mathrm{m}^{2}\right)$

\section{KESIMPULAN DAN SARAN}

\section{Kesimpulan}

1. Beberapa faktor yang mempengaruhi tarikan pergerakan kendaraan department store di Soloraya adalah total luas lahan dan total luas bangunan. Keduanya merupakan variabel bebas yang memiliki pengaruh kuat terhadap variabel terikat, yaitu tarikan pergerakan kendaraan. Pengaruh paling kuat ada pada variabel bebas total luas bangunan.

2. Model tarikan pergerakan kendaraan pada department store di Soloraya yang terbaik adalah model dari metode stepwise:

3. $\mathrm{Y}=14,455+0,005 \mathrm{X}_{2}$

4. Keterangan :

5. $\mathrm{Y}=$ Tarikan pergerakan kendaraan $(\mathrm{smp} / \mathrm{jam})$

6. $\mathrm{X}_{2}=$ Total luas bangunan $\left(\mathrm{m}^{2}\right)$

7. Model tersebut memiliki artian sebagai berikut.

8. Nilai konstan (a) pergerakan kendaraan sebesar 14,455 . Sedangkan faktor pengali (b) variabel bebasnya 0,005. Sedangkan variabel bebas yang pengaruhnya paling kuat adalah $\mathrm{X}_{2}$ (total luas bangunan). Adanya nilai konstanta dan kecilnya faktor pengali variabel bebas menunjukkan ada faktor lain yang mempengaruhi besarnya tarikan pergerakan kendaraan di department store di Soloraya selain total luas bangunan, namun tidak terjelaskan oleh persamaan regresi tersebut karena keterbatasan variabel yang diteliti.

9. Model persamaan regresi memiliki tanda positif yang menunjukkan bahwa makin besar pengaruh $\mathrm{X}_{2}$ (total luas bangunan), maka makin besar pula nilai tarikan pergerakan kendaraan. Dengan kata lain, model ini menjelaskan bahwa total luas bangunan $\left(\mathrm{X}_{2}\right)$ memiliki pengaruh terhadap tarikan pergerakan kendaraan $(Y)$.

\section{Saran}

Saran untuk penelitian selanjutnya adalah sebagai berikut.

1. Penelitian dengna topik sama dapat dilakukan pada tata guna lahan berbeda. 
2. Variabel bebas yang digunakan sebaiknya ditambah opsi lebih banyak, agar pengolahan data dapat dilakukan dengan sempurna.

3. Pemilihan variabel bebas sebaiknya dipilih berdasar karakteristik variabel yang dinilai kuat berpengaruh terhadap tarikan pergerakan, sehingga akan memberikna hasil lebih signifikan.

\section{REFERENSI}

Dwijayani, M., 2009. Analisis Pemodelan Tarikan Pergerakan Department Store (Studi Kasus Di Wilayah Surakarta). Skripsi. Fakultas Teknik. Universitas Sebelas Maret, Surakarta.

Mubarak, H. 2014. Pengarub Tarikan Perjalanan Pada Mall Pekanbaru dan Plaza Senapelan Terbadap Tingkat Pelayanan Saat Ini dan Proyeksi 5 Tabun ke Depan. Pekanbaru: Jurnal Fakultas Teknik Universitas Abdurrab Pekanbaru.

Niatika, U., 2018. Analisis Model Tarikan Perjalanan Masyarakat ke Kawasan Perdagangan/Perbelanjaan Kota Bandar Lampung. Skripsi. Fakultas Teknik. Universitas Lampung, Bandar Lampung.

Sihombing, F. 2013. Studi Bangkitan Perjalanan Pada Pusat Perbelanjaan Jenis Minimarket yang Dilengkapi Dengan Restoran. Depok: Jurnal Program Studi Teknik Sipil Universitas Indonesia Depok.

Tamin, Ofyar Z. 2003. Perencanaan dan Pemodelan Transportasi. Bandung: Penerbit ITB.

Raharjo, Sahid (2014, Februari). Tutorial Uji Heterokedastisitas dengan Uji Glejser SPSS. Dikutip 14 Juli 2019 dari SPSS Indonesia: http://www.spssindonesia.com/2014/02/uji-heterokedastisitasglejser-spss.html?m $=1$

Raharjo, Sahid (2014, Agustus). Uji Normalitas dengan Grafik. Histogram dan P-Plot SPSS. Dikutip 15 Juli 2019 dari SPSS Indonesia: http://www.konsistensi.com/2014/08/uji-normalitas-grafikhistogram-plot.html?m=1 